\title{
Application of Volume-Surface Hardening by High-Speed Water Flow for Improving Static and Cyclic Strength of Large-Scale Castings from Low-Carbon Steel
}

\author{
S.A. Nikulin, A.B. Rozhnov, T.A. Nechaykina, V.I. Anikeenko, \\ V.Yu. Turilina and S.O. Rogachev
}

\begin{abstract}
The article reveals the possibility of application of volume-surface hardening (VSH) by high-speed water flow for increasing static and cyclic strength of solebars of freight bogies manufactured from low-carbon cast steel 20 GL type. Formation of gradient structures with variable strength and ductility after VSH to the depth of 5-8 $\mathrm{mm}$ from the surface provides improved strength by 1.6-2.1 times compared to its normalized state and increases fracture resistance of solebars under static and cyclic loadings.
\end{abstract}

Keywords Hardening - Water flow - Low-carbon steel - Castings Solebars of freight bogies

S.A. Nikulin $(\bowtie) \cdot$ A.B. Rozhnov · T.A. Nechaykina · V.I. Anikeenko · V.Yu. Turilina $\cdot$ S.O. Rogachev

National Science and Technology University MISiS, Moscow, Russia

e-mail: nikulin@misis.ru

A.B. Rozhnov

e-mail: rojnov@nm.ru

T.A. Nechaykina

e-mail: nechaykinata@gmail.com

V.I. Anikeenko

e-mail: viki.zabo@gmail.com

V.Yu. Turilina

e-mail: veronikat@rambler.ru

S.O. Rogachev

e-mail: csaap@mail.ru

(C) The Author(s) 2018 


\section{Introduction}

Nowadays, improvement of fracture resistance of solebars of freight bogies aimed at ensuring their reliable operation is regarded to be an actual issue. Solebars of freight bogies are casting units of complex configuration manufactured from cast low-carbon steel 20 GL type. As for the heat treatment for the solebars of freight bogies, there is envisaged normalization or normalization with annealing. As a result of this type of heat treatment, solebars of freight bogies are characterized by relatively low strength properties (tensile strength approx. $550 \mathrm{MPa}$, yield strength approx. $360 \mathrm{MPa}$ ); and the internal residual tensile stresses on the surface might reach the level up to minus $50 \mathrm{MPa}$. This is the cause of their high sensitivity to stress concentrators and low cyclic life while being operated. The most effective way to eliminate the harmful influence of stress concentrators and to prolong the service life is their strengthening by volume-surface hardening method (VSH) by high-speed water flow (spray-quenching) [1, p. 544]. While applying controlled hardening by high-speed water flow, unlike traditional hardening in water or oil, heat transfer process can be significantly intensified [3, p. 257; 4, p. 201; 5, p. 4170]. This type of treatment generates a strength gradient in the product section and provides internal residual compressive stresses within its surface layers [1, p. 544]. Meanwhile VSH technology allows improving strength properties of solebars of freight bogies without changing the material and manufacturing technology of the castings.

Within the framework of this paper, we assume to investigate the impact of VSH by high-speed water flow on the microstructure and mechanical properties under static and cyclic loading of large-sized castings solebars of freight bogies as well as on their fragments manufactured from low-carbon cast steel. Previously we have already investigated the fracture mechanisms of solebar fragments [2, p. 31].

\section{Materials and Methods of Investigation}

Chemical composition of steel $20 \mathrm{GL}$ of the solebars of freight bogies having been studied, percent (mass): $0.19 \mathrm{C} ; 1.18 \mathrm{Mn} ; 0.38 \mathrm{Si}$; $0.24 \mathrm{Cu} ; 0.14 \mathrm{Cr} ; 0.12 \mathrm{Ni} ; 0.06$ $\mathrm{Al} ; 0.018 \mathrm{~S} ; 0.022 \mathrm{P}$. Fragments for study and testing (with thickness up to $20 \mathrm{~mm}$ ) were cut from the solebars of freight bogies belonging to one consignment. Layout of the cutting is shown in Fig. 1.
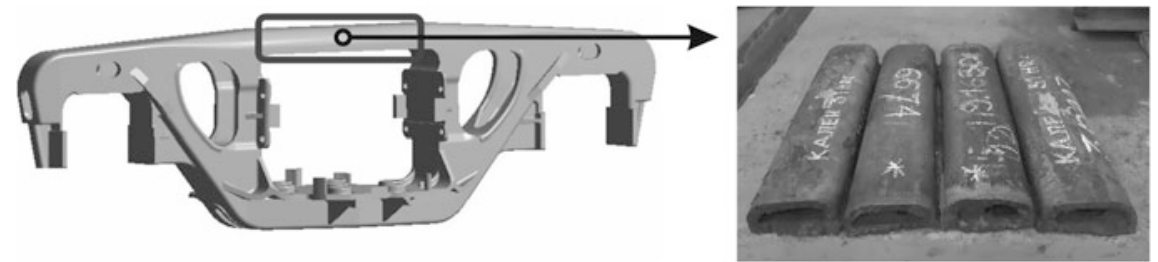

Fig. 1 The solebar and cut fragments before the test 
There has been conducted a comparative analysis of the structure and mechanical properties of the solebars of freight bogies in normalized state (excerpt for $2 \mathrm{~h}$ at $930-960{ }^{\circ} \mathrm{C}$, cooling in air) and after VSH effected at $890-1000{ }^{\circ} \mathrm{C}$ with cooling to $20-30{ }^{\circ} \mathrm{C}$ by high-speed water flow speeds of $800{ }^{\circ} \mathrm{C} / \mathrm{sec}$.

Microstructure was studied applying Axiovert 40 MAT (Carl Zeiss) optical microscope and HITACHI TM-1000 scanning microscope operated in the mode of secondary electrons. Quantitative metallographic analysis was conducted applying Thixomet software environment.

Vickers microhardness was measured by Micromet 5101 (Buehler) microhardness tester and digital camera Mitron MTV-1 62W1P under load $1 \mathrm{H}$ applied within $10 \mathrm{~s}$.

Mechanical tensile test of proportional flat samples with thickness of $3.5 \mathrm{~mm}$ have been carried out on Instron 150 LX universal testing machine with $1 \mathrm{~mm} / \mathrm{min}$ loading rate at room temperature. Tensile testing samples have been cut out of the solebar fragments after the VSH, close to hardened surface.

Three-point bending tests of solebar fragments have been carried out at room temperature with a loading rate $25 \mathrm{kN} / \mathrm{min}$ on the EBMC-200 PU test machine. The test has been finished when the first macro-cracks have been detected and identified by acoustic emission (AE) measurements. Alongside, there have been identified critical (before the advent of the crack) strain and residual deflection of top wall fragment after removal of the load.

Vertical loading three-point bending type cycle test of full-scaled solebars of freight bogies has been carried out on facility with electrohydraulic loading device equipped with hydropulser with maximum effort at 100 ton-force and applying specially designed loading supports (Fig. 2). Tests have been carried out in asymmetric loading mode with loading frequency $5 \mathrm{~Hz}$. Basic distance between

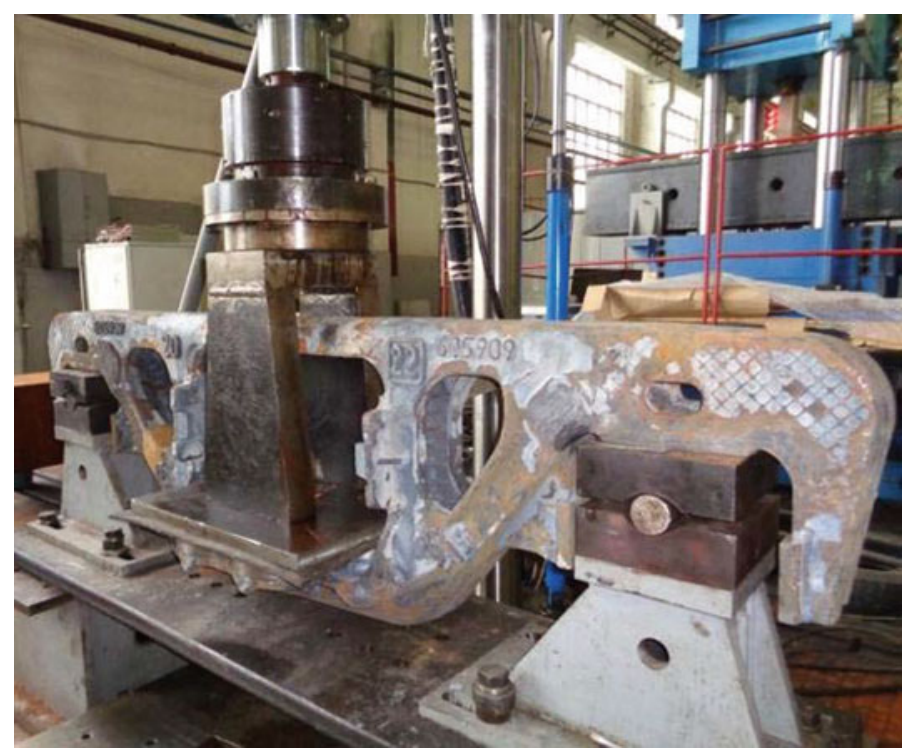

Fig. 2 Cyclic testing of the solebar 
supports has been $1850 \mathrm{~mm}$. Cyclic loading has been carrying out until fracture of solebars of freight bogies at base load cycles equal to $2 \times 10^{6}$.

\section{Results and Discussion}

Microstructure. Microstructure analysis outcomes demonstrated that after normalization the fragments from 20GL steel have a ferritic-pearlitic structure with ferrite grains sized $25 \pm 5 \mu \mathrm{m}$ and perlite colonies with plates of cementite having thickness of $0.1-0.3 \mu \mathrm{m}$ and interlamellar distance of $0.3-0.7 \mu \mathrm{m}$ (Fig. 3a, d).

VSH leads to creation of gradient structure in the fragment. As for the surface layer of the sample after VSH (at a distance of 2-3 $\mathrm{mm}$ from the surface), there has been identified mixed martensite-like structure (Fig. 3b, e). There are troosto-martensite segment with excess ferrite on grain boundaries. On the depth from the surface layer of the fragment after $\mathrm{VSH}$, the shaped structure representing a ferrite-cementite composite with interlamellar distance of no more than $0.2 \mu \mathrm{m}$, maintaining orientation of fine-needled martensite is being formed. As for the middle part of the sample fragment, there has been identified mixed structure (ferritic-cementite composite (sorbite) with small percentage of allocations of different morphology ferrite on grain boundaries) ensuring high toughness of the core (Fig. 3c, f).

Microhardness. After the normalization process has been carried out, microhardness along the whole section of fragments achieved 150-200 HV. After VSH there exists a hardened area with microhardness of 400-480 HV to the depth of 5-8 mm. In the central area of the fragment microhardness achieved 300-380 HV. Thus, the application of VSH leads to improvement of hardness at subsurface layers
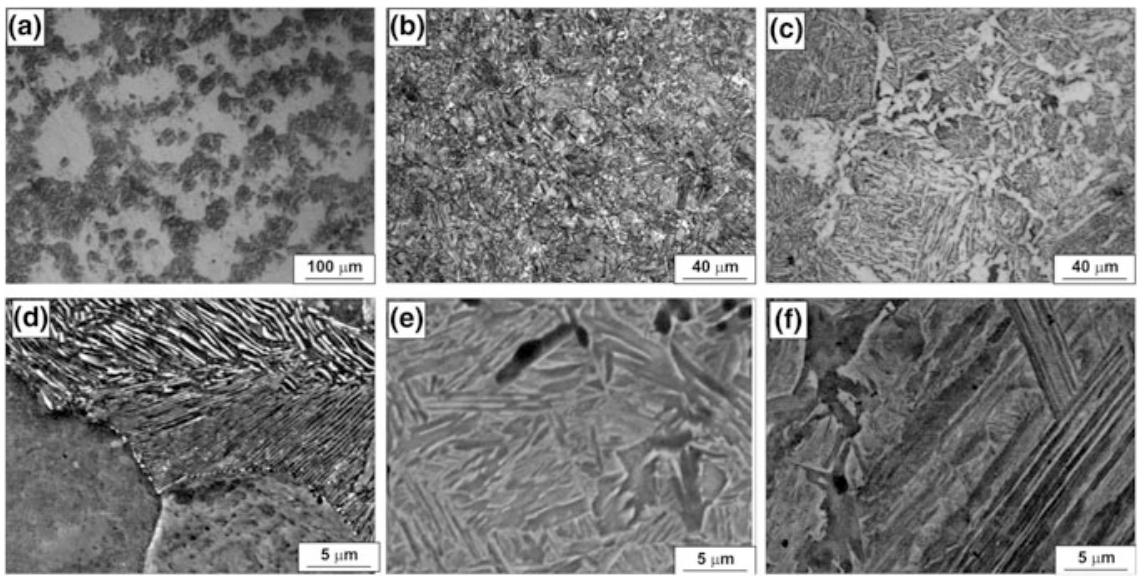

Fig. 3 The microstructure of the samples after normalization (a, d) and after VSH in the surface layer $(\mathbf{b}, \mathbf{e})$ and in the core of the sample $(\mathbf{c}, \mathbf{f})$ 
in the solebars of freight bogies to the depth up to $5-8 \mathrm{~mm}$ by $2.0-2.5$ times compared to normalized state.

Static and cyclic strength. Comparison of mean values of mechanical properties of samples from hardened surface layer of fragments of solebars of freight bogies after VSH and the samples from fragments of solebars of freight bogies after normalization demonstrates that VSH ensures improved tensile strength by 1.6-1.8 times (up to $965 \mathrm{MPa}$ ) and yield strength by 1.9-2.1 times (up to $710 \mathrm{MPa}$ ) compared with normalized status provided that relative elongation is not below $10 \%$.

Three-point bending tests of the solebars of freight bogies fragments demonstrated that VSH affects the kinetics of deformation defects accumulation. Layer cracks appeared in hardened layer do not propagate until the maximum load has been applied and a main crack emerging further impedes within ductile core. When loading a three-point bending of the fragments after the normalization the main crack emerges even before the peak load, and its propagation takes place continuously over time until the final failure of the fragment. The loss of bearing capacity of fragments after normalization occurs under load of 1.5-1.7 times lower than for fragments after VSH.

Resistance to fatigue failures of the solebars of freight bogies, after VSH is by $20 \%$ higher than for the solebars of freight bogies in a normalized state. The value of the fatigue resistance safety factor of the solebars of freight bogies after VSH is 2.4 , compared with a value of 2.1 for normalized solebars of freight bogies.

\section{Conclusions}

1. There has been demonstrated improvement of strength properties of large-scale products (thickness up to $20 \mathrm{~mm}$ ) manufactured from low-carbon cast steel 20 GL, e.g., solebars of freight bogies when applying volume-surface hardening (VSH) by high-speed flow of water.

2. VSH leads to creation of gradient structure along the fragment wall thickness: hardened surface layer thickness of 5-8 mm with martensite-like structure and toughness core with sorbite and ferrite structure.

3. The VSH leads to increased tensile strength by 1.6-1.8 times and yield strength by 1.9-2.1 times in surface layers of the solebars of freight bogies compared to the ones in normalized state.

4. Solebars of freight bogies thermal hardening by VSH method provides their improved resistance to fracture under cyclic loading.

Acknowledgments Researches are carried out with the financial support of the state represented by the Ministry of Education and Science of the Russian Federation. Agreement no. 14.581.21.0009 03. Oct 2014. Unique Project Identifier: RFMEFI58114X0009. 


\section{References}

1. Fedin, V.M., Borts, A.I.: Volume-surface hardening of freight bogie springs from steels with reduced and controlled hardenability. Metal Sci. Heat Treat. 51(11-12), 544-552 (2009)

2. Nikulin S.A, Khanzhin V.G., Oguenko V.N., Nikitin A.V., Rozhnov A.B., Turilina V.Yu., Rogachev S.O.: Kinetics and mechanisms of static failure of cast solebar fragments during bending. Deformatsiya i razrushenie materialov. 3, 31-35 (2016). [in Russia]

3. Schüttenberg, S., Hunkel, M., Fritsching, U., Zoch, H.-W.: Proceedings of 5th international and European conference on quenching and control of distortion, 25-27 April 2007, pp. 257-264. Berlin

4. Stark, P., Schuettenberg, S., Fritsching, U.: Spray quenching of specimen for ring heat treatment. WIT Trans. Eng. Sci. 70, 201-212 (2011)

5. Li, Z., Ferguson, B.L., Nemkov, V., Goldstein, R., Jackowski, J., Fett, G.: Effect of quenching rate on distortion and residual stresses during induction hardening of a full-float truck axle shaft. J. Mater. Eng. Perform. 23(12), 4170-4180 (2014)

Open Access This chapter is licensed under the terms of the Creative Commons Attribution 4.0 International License (http://creativecommons.org/licenses/by/4.0/), which permits use, sharing, adaptation, distribution and reproduction in any medium or format, as long as you give appropriate credit to the original author(s) and the source, provide a link to the Creative Commons license and indicate if changes were made.

The images or other third party material in this chapter are included in the chapter's Creative Commons license, unless indicated otherwise in a credit line to the material. If material is not included in the chapter's Creative Commons license and your intended use is not permitted by statutory regulation or exceeds the permitted use, you will need to obtain permission directly from the copyright holder. 